\title{
New strategies for active finding of leprosy cases in the Amazonian region
}

\section{Dony Cristioney Castilho de Campos ${ }^{[1]}$, Ana Paula Barzan Dutra ${ }^{[1]}$, Vagner Lucas Suares ${ }^{[1]}$, Paulo Abner Cardoso de Carvalho ${ }^{[1]}$ and Luís Marcelo Aranha Camargo ${ }^{[2],[3]}$}

[1]. Faculdade de Ciências Biomédicas de Cacoal, Cacoal, Rondônia, Brasil. [2]. Instituto de Ciências Biomédicas 5, Universidade de São Paulo, Monte Negro, Rondônia, Brasil. [3]. Faculdade São Lucas, Porto Velho, Rondônia, Brasil.

\begin{abstract}
Introduction: The use of the Self-Image Form (SIF) expands the identification of active leprosy cases to neighbors of index cases. Methods: The SIF was used to screen two groups: case (neighbors of index cases of leprosy) and control (individuals residing next to houses without leprosy) group. A specialist investigated suspected leprosy cases for disease confirmation. Results: New cases of leprosy were diagnosed in the case group $(\mathrm{n}=7,8.6 \%)$, but not the control group. Conclusions: The new surveillance strategy is inexpensive, efficient, and feasible within a primary health strategy. Future studies can help improve the use of the SIF.
\end{abstract}

Keywords: Leprosy. Surveillance. Amazônia. Public Health.

Leprosy is a chronic infectious disease caused by Mycobacterium leprae that significantly affects public health in Brazil. In the Americas, Brazil accounts for $90 \%$ of leprosy cases and ranks second globally in the absolute number of cases and incidence $\left(47,000\right.$ new cases/year) ${ }^{(1)}$. Leprosy affects people of any age but is more prevalent among adults ${ }^{(2)}$. It has a broad range of clinical manifestations, with opposing stable poles at the extremes and unstable intermediate forms that can acquire the clinical and immune features of either pole, depending on the presence of risk factors ${ }^{(3)}$. It affects the skin, mucous membranes, and peripheral nerves, and the bacilli spread to the peripheral nerves and skin in a few infected individuals.

Leprosy is transmitted by upper airway secretions via intimate contact between healthy and untreated infected individuals. The incubation period lasts two to five years ${ }^{(4)}$. The most susceptible population includes the family contacts of multibacillary cases, followed by extra-domiciliary contacts and the contacts of paucibacillary cases ${ }^{(5)}$.

For active case finding among contacts, the Brazilian Ministry of Health (BMH) recommends interviewing and performing physical examinations for all household contacts of leprosy patients (index cases). In this study, we sought to broaden the scope of such active case finding by using the BMH's SelfImage Form (SIF) and including the neighbors of index cases. The SIF is a one-page form that is completed by the patient or the parents and collects information about the symptoms and

Corresponding author: Dr. Luís Marcelo Aranha Camargo. ICB/USP-Monte Negro. Rua Francisco Prestes 1234, Setor II, 76888-000 Monte Negro, Rondônia, Brasil. Phone: 5569 3530-2349

e-mail: spider@icbusp.org

Received 19 January 2015

Accepted 15 April 2015 clinical signs of leprosy as well as who has had contact with the patients with leprosy. If the information provided on the form is suspicious for leprosy, the patient is examined by a specialist, and complementary tests are performed.

The aim of this study was to determine if the surveillance of extra-domiciliary contacts (neighbors) and use of the SIF increase the reporting of leprosy cases, thereby contributing to the development of simple, low-cost, and easy-to-apply tools for the epidemiological surveillance of leprosy that are applicable within the context of a primary health strategy (PHS).

In the municipality of Monte Negro $\left(63^{\circ} 10^{\prime} 00 \mathrm{~W}, 12^{\circ} 40^{\prime} \mathrm{S}\right)$, which is in the State of Rondônia in the north of Brazil, there are approximately 14,091 inhabitants ${ }^{(6)}$. Forty individuals were diagnosed with leprosy (index cases) between 2009 and 2013 and were included in another study designed to find new cases of disease among two groups: household contacts (secondary data) and neighbors. For the purpose of comparisons, the study population, that was conducted between 2013-1014, was divided into two groups: case group including the neighbors of the index cases and control group including neighbors of households without leprosy cases and at least 200 meters away from any index case. This distance was empirically established by the authors, based on the findings of Barreto et $\mathrm{al}^{(7)}$.

The SIF was completed by both groups. The leprosy diagnosis was confirmed based on the criteria described in the BMH Guidelines ${ }^{(8)}$, to which the following tests were added, as needed: dermal scraping, sensitivity testing using monofilament nylon fibers (esthesiometer), reaction to $1 \%$ histamine and $1 \%$ pilocarpine, and anatomical pathology examination. Subjects were classified as with (multibacillary or paucibacillary) or without leprosy. Individuals who reported the presence of a spot and/or contact with patients with leprosy but did not meet the diagnostic criteria for leprosy were assessed for differential diagnoses. 
The data were entered in an Excel spreadsheet, and statistical analysis was performed using OPEN EPI (www.openepi.com) software. Comparisons between qualitative variables were performed using the Yates test, with significance set at $>95 \%$.

In the case group, 194 SIFs were completed by all of the residents of homes adjacent to (facing, on the left and right sides, and behind) the homes of the index cases diagnosed with leprosy between 2009 and 2013. A total of 113 individuals denied both the presence of a spot and contact with an individual with leprosy. Of the remaining 81 (41.7\%) individuals, 44 individuals reported the presence of a spot on some part of the body, and 37 denied the presence of any spot but reported contact with a treated or untreated individual with leprosy. Therefore, the healthcare staff performed consultations with these 81 individuals. The consultations included a full clinical interview focusing on leprosy and a physical examination, which was performed with the participants in their underclothes for a full-body inspection to identify the reported spots and/or anesthetic areas. Of these 81 patients, $75(91.3 \%)$ individuals were deemed healthy, and leprosy was confirmed in 7 (8.6\%) patients, 5 paucibacillary and 2 multibacillary.

Of the 196 SIFs completed in the control group, 160 individuals denied both the presence of spot and contact with any individual diagnosed with leprosy. Of the remaining 36 individuals (37.5\%), $26(26 / 160,13.3 \%)$ reported having a spot somewhere on their body, and $10(10 / 160,5.1 \%)$ denied having spot but reported contact with a treated or untreated individual with leprosy. Thus, the healthcare staff performed consultations with these 36 individuals; none were diagnosed with leprosy.

Given the 40 originally diagnosed leprosy cases between 2009 and 2013, the 7 cases identified in the present study represent a $17.5 \%(7 / 40)$ increase in the total reported cases during the period. In addition, secondary data provided by the municipal basic health unit showed that 13 (7.2\%) new cases had been found among 181 household contacts, of the original 40 cases, representing an increase of $32.5 \%(13 / 40)$ in the notification rate. Collectively, the new cases diagnosed using the traditional surveillance method or active search between neighbors and the use of the SIF account for an increase of $50 \%(20 / 40)$ in the total cases reported between 2009 and 2013.

The differences in rates detected between household contacts and neighbors were not significant (Yates $\chi^{2}=1.714$, $\mathrm{p}=0.09536$ ).

Of the 44 individuals in the case group who reported the presence of a spot on some part of the body (44 of 81 positive SIF responses, $54.3 \%$ ), dermatitis and the following skin diseases were diagnosed: lentigo/nevus $(21 / 81,25.9 \%)$, pityriasis versicolor $(12 / 81,14.8 \%)$, pityriasis alba $(6 / 81,7.4 \%)$, tinea corporis $(4 / 81,4.9 \%)$, basal cell carcinoma $(1 / 81,1.2 \%)$, chromoblastomycosis $(1 / 81,1.2 \%)$, and others $(3 / 81,3.6 \%)$.

Of the 26 individuals in the control group who reported the presence of a spot on some part of the body ( 26 of 36 positive SIF responses, $72.2 \%$ ), the following skin diseases were diagnosed: lentigo/nevus $(9 / 36,25 \%)$, pityriasis versicolor $(5 / 36,13.8 \%)$, pityriasis alba $(4 / 36,11.1 \%)$, tinea corporis $(1 / 36,2.7 \%)$, and basal cell carcinoma $(1 / 36,2.7 \%)$.
The findings of this study support the hypothesis that searching for cases among the neighbors of individuals with leprosy using the MHSIF increases the notification of new cases of leprosy, in this case by $17.5 \%(7 / 40)$.

Although the single epidemiological surveillance tool currently available is efficient at detecting new cases of leprosy (and other skin diseases) in the investigation of household contacts $^{(9)(10)}$, recent evidence from northeastern Brazil indicates that investigating extra-domiciliary contacts is efficacious; the rates of detection were similar between household contacts $(2.9 \%)$ and neighbors $(2.1 \%)$, and active case finding among extra-domiciliary contacts increased the number of diagnosed cases by $72.4 \%{ }^{(11)}$. Furthermore, a study conducted in northwestern Bangladesh, a densely populated area in which leprosy is highly endemic, suggested that the neighbors of leprosy patients might be a high-risk group ${ }^{(12)(13)}$

A review of records of leprosy from 2000 to 2010 in Uberaba in the state of Minas Gerais, Brazil identified a significant increase in cases over that period, especially in $2004^{(14)}$. This coincided with a municipal campaign of active case finding in the community (i.e., among non-contacts of leprosy cases). Therefore, flaws in the detection of new leprosy cases are present due to the inefficiency of existing epidemiological surveillance.

The results of this study emphasize the relevance of active leprosy case finding among neighboring homes with the use of the SIF, in addition to household contacts of cases, particularly in areas where the incidence is high. However, even the SIF could be improved by the inclusion of a question about the presence of anesthetic areas (not just spot), which is not in the current SIF. There were no cases of leprosy identified in the investigation of neighbor contacts in the control group who lived at least 200 meters away from any index case, which suggests that 200 meters might be the minimum search radius for neighbor contacts in this municipality.

In addition to identifying new cases of leprosy, the use of the SIF with a subsequent physical examination resulted in diagnosis of other skin diseases, including skin cancer in 2 individuals ( 1 in the control group) and chromoblastomycosis, which is extremely important from the perspective of early therapeutic intervention.

According to Hacker et al. ${ }^{(9)}$, cases diagnosed through contact surveillance are detected earlier in the disease progression, have lower initial and final bacterial indices, have lower initial and final disability grades, and have a lower prevalence of disease reactions. To achieve control of transmission through early diagnosis of leprosy, changes in the protocols for active leprosy case finding among contacts must be improved, including broadening the scope of investigation to neighbors within at least a 200-meter radius. This strategy, combined with the use of a modified SIF (inclusion of a question about the presence of anesthetic areas), would be a low-cost, efficient, and feasible implementation within the PHS setting. A broad-scope investigation including household and extradomiciliary (neighbors) contacts within a 200-meter radius of index cases allows the detection of other skin conditions that deserve intervention. Future studies might establish a more 
precise minimum radius for active case finding among contacts and improve the SIF as a screening tool for leprosy cases.

\section{Ethical considerations}

This study was approved by the Brazilian Research Ethics Committee under protocol number 18669213.3.0000.5467.

\section{ACKNOWLEDGMENTS}

We would like to thank the Institute of Biomedical Science of the University of São Paulo for the budget and the people from the county of Monte Negro who participated in the study. We would also like to thank Prof. Sergio de Almeida Basano, from Centro de Medicina Tropical de Rondônia (CEMETRON), for reviewing the manuscript.

\section{CONFLICT OF INTEREST}

The authors declare that there is no conflict of interest.

\section{FINANCIAL SUPPORT}

The Institute of Biomedical Science of the University of São Paulo provided financial support for this study.

\section{REFERENCES}

1. Araújo MG. Hanseníase no Brasil. Artigo de atualização. Rev Soc Bras Med Trop 2003; 36:373-382.

2. Barbieri CLA, Marques HHS. Hanseníase em crianças e adolescentes: revisão bibliográfica e situação atual no Brasil. Pediatria 2009; 31: 281-290.

3. Foss NT. Hanseníase: aspectos clínicos, imunológicos e terapêuticos. An Bras Dermatol 1999; 74:113-119.
4. Goulart IMB, Penna GO, Cunha G. Imunopatologia da hanseníase: a complexidade dos mecanismos da resposta imune do hospedeiro ao Mycobacterium leprae. Rev Soc Bras Med Trop 2002; 35: 365-375.

5. Pinto Neto JM, Villa TCS, Mencaroni DA, Gonzáles RC, Gazeta CE. Considerações epidemiológicas referentes ao controle dos comunicantes de hanseníase. Hansen Int 2002; 27:23-28.

6. Instituto Brasileiro de Geografia e Estatística (IBGE) (Internet). Censo Demográfico 2010. Brasília: IBGE; 2010. (Cited 2015 January 15). Available at: www.ibge.gov.br/

7. Barreto JG, Bisanzio D, Guimarães LS, Spencer JS, VazquezProkopec GM, Kitron U, et al. Spatial analysis spotlighting early childhood leprosy transmission in a hyperendemic municipality of the brazilian amazon region. PLoS Negl Trop Dis 2014; 8:e2665.

8. Ministério da Saúde. Guia para o controle da hanseníase. Cadernos de Atenção Básica, n. 10. Brasília: Ministério da Saúde; 2002.

9. Hacker MA, Duppre NC, Nery JA, Sales AM, Sarno EN. Characteristics of leprosy diagnosed through the surveillance of contacts: a comparison with index cases in Rio de Janeiro, 19872010. Mem Inst Oswaldo Cruz 2012; 107:49-54.

10. Sampaio PB, Rossi TL, Cerutti Junior C, Zandonade E. Spatial analysis of new cases of leprosy in the State of Espírito Santo, Brazil, between 2004 and 2009. Rev Soc Bras Med Trop 2012; 45:380-384.

11. Moura ML, Dupnik KM, Sampaio GA, Nobrega PF, Jeronimo AK, do Nascimento-Filho JM, et al. Active surveillance of Hansen's disease (leprosy): importance for case finding among extradomiciliary contacts PLoS Neg1 Trop Dis 2013; 7:e2093.

12. Hoeven TA, Fischer EA, Pahan D, Richardus JH. Social distance and spatial distance are not the same, observations on the use of GIS in leprosy epidemiology. Epidemiol Infect 2008; 136: 1624-1627.

13. Feenstra SG, Nahar Q, Pahan D, Oskam L, Richardus JH. A Qualitative Exploration of Social Contact Patterns Relevant to Airborne Infectious Diseases in Northwest Bangladesh. J Health Popul Nutr 2013; 31:424-434.

14. Miranzi SSC, Pereira LHM, Nunes AA. Perfil epidemiológico da hanseníase em um município brasileiro no período de 2000 a 2006. Rev Soc Bras Med Trop 2010; 43:62-67. 